\title{
Continuing medical education for paediatricians
} British Paediatric Association, Academic Board Subcommittee on the Pilot Scheme for
Continuing Medical Education

This is the seventh in a series on medical education.

\author{
British Paediatric \\ Association, $5 \mathrm{St}$ \\ Andrews Place, \\ Regent's Park, London \\ NW1 4LB \\ Members of the \\ subcommittee: $\mathrm{S} \mathrm{J}$ \\ Shribman (convenor), \\ G C Soulby, T M Little, \\ E R Verrier Jones, \\ D P Davies (chairman of \\ the Academic Board), \\ R J Topping, and \\ A M C Clark.

\begin{abstract}
Background
Continuing medical education (CME) is the continuing education - part of the professional development - of all practising consultants in the NHS, the universities and independent practice, along with other non-training career grades of staff who look after children in hospital and the community. CME is a professional responsibility for all doctors, to enhance their clinical effectiveness and competence by maintaining and improving standards, interest, and enthusiasm in their practice. Nationally a lot of thought is going into this subject at present, with the medical royal colleges and their faculties all developing their own schemes.
\end{abstract}

The obligation to keep up to date is not new. It has always been part of professional practice. Paediatricians have hardly to be reminded of the wide range of educational activities they already participate in to keep up to date. At the same time, there can be no doubt that some doctors have had more opportunity than others to engage in CME activities, in terms of both time and availability, as well as accessibility to and resources for suitable activities. As a result of these and other concerns, the time has been fast approaching when a formal programme for $\mathrm{CME}$ is looked for. The public, government, peers, and managers expect paediatricians to be able to demonstrate that they are continuing their professional development. Doctors are increasingly expected to be accountable, as are other professional groups.

Mindful of the national picture and following the chief medical officer's consultation paper on $\mathrm{CME},{ }^{1}$ the British Paediatric Association (BPA), in line with other colleges and faculties, decided in 1994 to develop its own scheme with the object of embracing the needs of all doctors dealing with children in career grade posts in the United Kingdom. The task of preparing this was given to a subcommittee of the Academic Board, Convenor Dr Sheila Shribman (consultant paediatrician in community child health, Northampton).

At the outset it was considered to be essential that the present activities attended by paediatricians should be clearly delineated in order to ensure a scheme that not only fulfilled the expectations of others but met the needs of paediatricians. In September 1994 the BPA published the pilot scheme proposals. The system was based on units of CME time ( 1 unit $=1$ hour) for a wide range of educational activities, an approach shared by the various professional groups who had already introduced CME, notably the Royal College of Obstetricians and Gynaecologists, the Royal College of Radiologists, and the Royal College of General Practitioners. The initial model specified six categories of CME activity, by venue and level of organisation (see appendix). However, it was proposed that neither the broad content of educational activity, nor any one particular venue, should contribute more than $50 \%$ of the total CME over five years. A range of activities was to be selected by the individual exercising flexibility in order to achieve the balance between broad based and special activities necessary to suit particular needs.

Central to the pilot scheme recommendations was that CME activities should be recognised depending on whether or not the activity takes place in protected time often with study leave. External CME, defined as work involving interaction with colleagues outside the individual's own department and usually requiring study leave in protected time, included courses organised by the BPA, the royal colleges, the Royal Society of Medicine, and many specialists' societies, as well as personal visits to outside institutions to acquire new skills or update knowledge, and attendance at national and international symposia and workshops. Internal $C M E$, not requiring study leave in protected time, included unit clinical meetings, especially those involving a multidisciplinary approach, hospital specialists' meetings, grand rounds, and clinical audit meetings. Paediatricians were to keep record sheets for two consecutive six month periods and submit them upon the completion of each period.

Integral to the philosophy of CME is that specialists subscribe to and regularly read appropriate general and specialist journals as a fundamental continuing learning activity, but it was not proposed that this activity should contribute to the formal CME programme. Also, at variance with the approach adopted by some others, examination activities, either undergraduate or postgraduate, and research activities, whether in the preparation of papers or presentations, were not to be included; it was felt that although on occasions undoubtedly contributing to learning, these activities would be in general more difficult to validate.

Initially the CME subcommittee had 


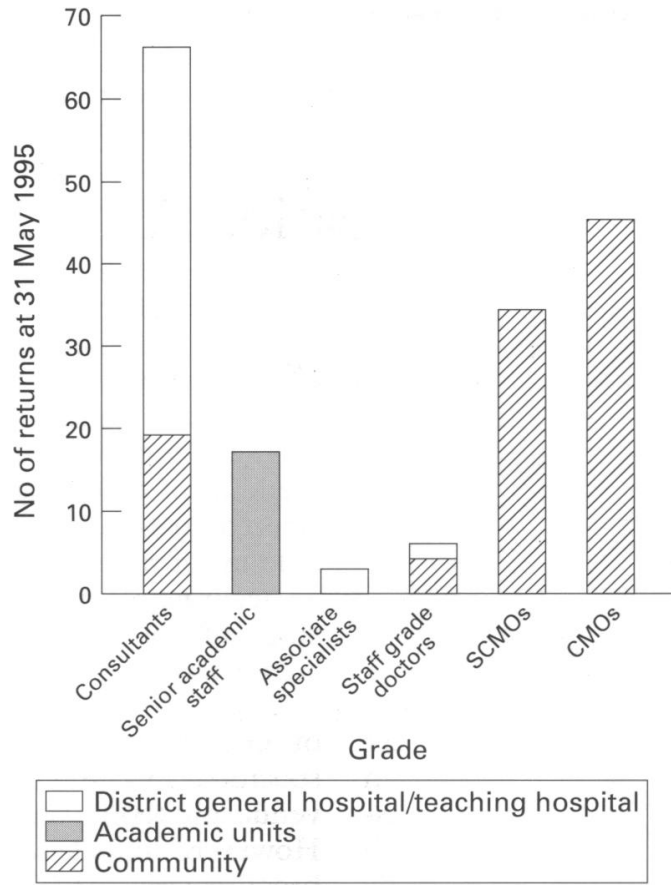

Figure 1 Returns by grade and type of work (1 October 1994-31 March 1995); SCMOs=senior clinical medical officers, CMOs=clinical medical officers.

proposed that 10 days' statutory study leave per year should be taken to gain external CME, up to a total of 60 hours per year, with an additional 60 hours of internal activity. However, this view was not widely supported in the Committee of CME Directors from the medical royal colleges and their faculties. It was agreed instead that following the CME requirements proposed by other organisations, the pilot scheme should set an initial basic minimum target of 50 hours per year, building up after a couple of years to 100 hours, half of the credits coming from external CME. The allocation of time proposed was three hours for a half day and a nominal five hours for a whole day, with a CME certification period of five years. Complex weighting systems for different activities were considered and rejected.

Many possible problems, for example the applicability of the scheme to those in part time employment, in small units and in community paediatric practice, were considered and in the light of the questions raised, a pilot study was felt to be essential. An exercise in two contrasting regions, Wales and South East Thames, was decided upon to explore the feasibility of the initial proposals for a formalised programme of CME.

\section{Methods and results}

The district advisers (now designated BPA tutors) in Wales and the South East Thames region were contacted to establish the cohort of career grade paediatricians within the scope of the pilot scheme. These included consultant paediatricians in district general hospitals, the community and academic units, senior clinical medical officers, clinical medical officers, associate specialists, and staff grade doctors. Individuals were written to with information about the scheme and invited to participate. Each doctor was sent a copy of the BPA document Continuing Medical Education for Trained Paediatricians - Recommendations by the Academic Board for a Pilot Scheme to Implement $C M E,{ }^{2}$ and a record sheet for the first six month period, 1 October 1994 to 31 March 1995. Participants were asked to enter all CME activities undertaken during this period on the form, which was to be returned to the BPA office at the beginning of April; a second record sheet for the period 1 April 1995 to 30 September 1995 would than be sent out. In each six month period a total of 25 hours of CME activity was the target, of which at least $50 \%$ was to be external CME.

The final number identified as eligible and assumed to be participating in the pilot scheme was 421 , excluding five who advised the BPA that they would not be taking part. By 31 May 1995 (two months after completing the first six month period), 171 returns $(40 \cdot 6 \%$ of those assumed to be participating) had been received from the two regions in almost equal proportions - South East Thames $87(50.9 \%)$ and Wales $84(49 \cdot 1 \%)$. Of those who had replied by this date, $101(59 \cdot 1 \%)$ were members of the BPA. The type of work engaged in by the 171 respondents comprised district general hospital/teaching hospital $52(30.4 \%)$, academic units $17(9 \cdot 9 \%)$, and community 102 (59.7\%).

Participation at 31 May 1995 by grade and type of work is shown in fig 1 .

Analysis of the record sheets received showed that 141 of the respondents $(82.5 \%)$ achieved a total of 25 hours or more of CME activities in the first six months. The number obtaining more than 12 hours external CME in this period was $130(76 \cdot 0 \%)$. However, if the projected CME requirement had been 50 hours in the six month period (as is expected to apply with a target of 100 hours CME per annum to be introduced in a couple of years)

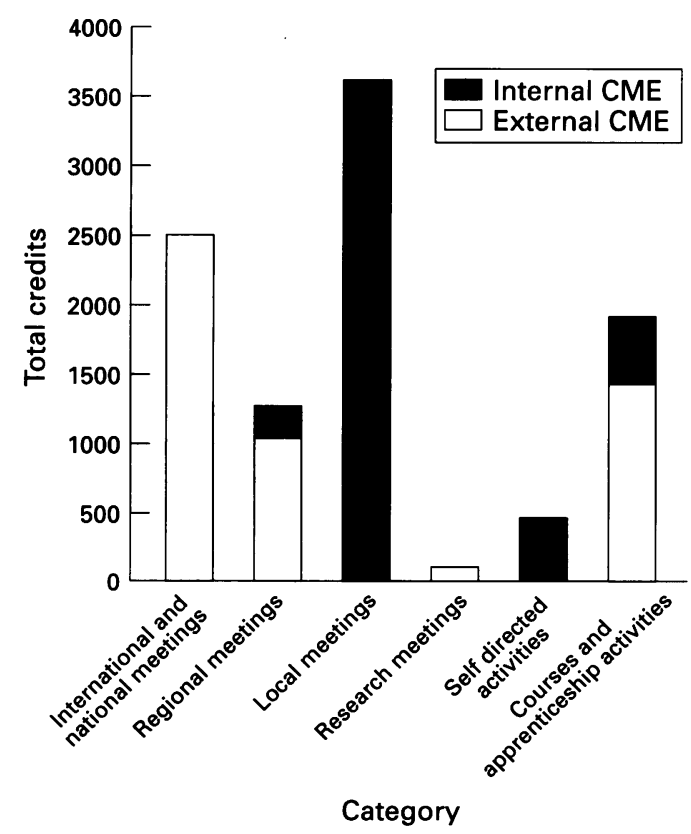

Figure 2 Distribution of CME credits claimed (1 October 1994-31 March 1995). 


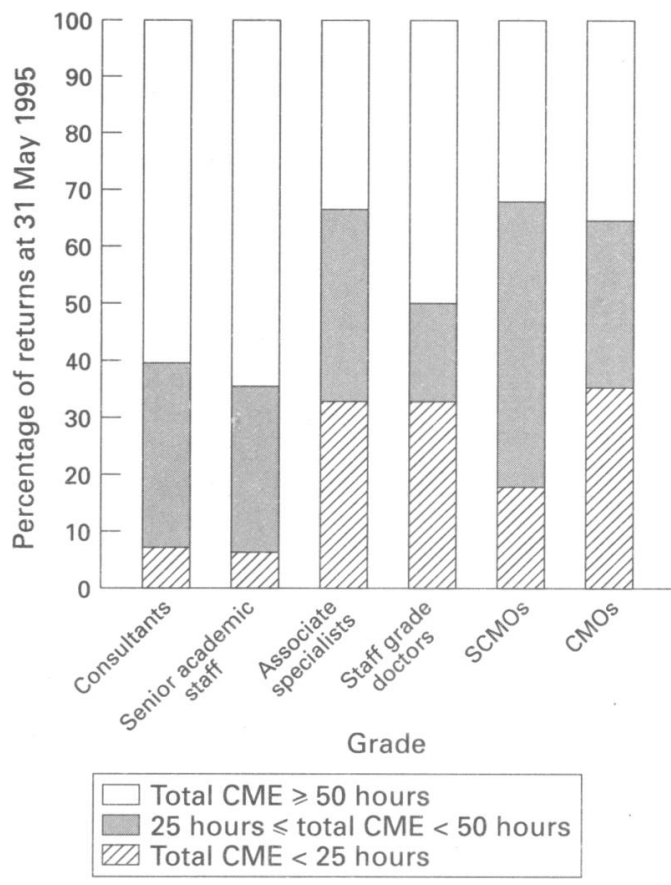

Figure 3 Percentage attaining CME targets within grades: basic target 25 hours (1 October 1994-31 March 1995); SCMOs= senior clinical medical officers, CMOs=clinical medical officers.

then only $82(48 \cdot 0 \%)$ would have satisfied that target, with $87(50.9 \%)$ obtaining 25 hours or more external CME.

Figure 2 shows the distribution of $\mathrm{CME}$ credits claimed by participants. As expected, most external CME was from attendance at national and international meetings; internal CME was mainly from attendance at local meetings. Some participants claimed a significant number of hours as a result of courses, such as MSc programmes.

Figure 3 shows the percentage of respondents within each grade who attained the CME targets. The majority of those who did not achieve the minimum target of 25 hours $\mathrm{CME}$ in the first six months were clinical medical officers. Associate specialists and staff grade doctors also appear to have had difficulty in achieving the minimum target, although it has to be recognised that the number of participants/returns from doctors in these grades was very low. While $48 \%$ of the respondents achieved a total of 50 hours or more in this period and would therefore be likely to reach the BPA's long term target of 100 hours per year, those not achieving this level included not only clinical medical officers and senior clinical medical officers but also a significant number of consultants in hospital practice.

\section{VERIFICATION OF THE SCHEME}

As a means of verifying the pilot scheme data, a randomly selected $10 \%$ of those who had achieved the initial target of 25 hours were contacted and asked to provide evidence to verify their CME record as advised in the pilot scheme document. There was a poor response to this request, with only seven replying. One sent documentation relating to all activities entered on the return, while a further two were able to supply partial verification. However, helpful comments were received; these suggested that the method of monitoring CME returns for a national scheme would require further consideration.

Participants and others in the BPA also submitted comments on a number of aspects of the pilot scheme. Teaching, including postgraduate presentations, was regarded by some as a valid CME activity, both in terms of delivery and time spent on preparation. This was anticipated, but as mentioned above, methods of validating such activities were considered to be difficult, both in assessing the amount of time spent on them and in keeping an accurate record with respect to self directed study of this type. Other topics raised in this area related to the exclusion of examination activities and also journal reading. A small number of participants commented on the recording system. Sessional workers emphasised problems arising from the limited amount of study leave available to them and, in some instances, the limited funding. Shortage of doctors, lack of staff cover, and other medical commitments were also highlighted as important practical impediments to the achievement of the basic minimum target for CME.

\section{Discussion}

Implementing this pilot scheme has been an invaluable exercise, identifying as it has some important problems that have been heeded in drawing up final recommendations for the BPA national scheme due to start on 1 January 1996. Especially useful has been the highlighting of problems which some groups of doctors have with CME - particularly certain community doctors and paediatricians working in small units. Many of the former were not members of the BPA, the medical royal colleges or their faculties. In the course of the pilot there have been some queries as to whether there is a need for the BPA to undertake its own scheme for CME. Why not, the argument has gone, participate in the CME scheme of the Royal Colleges of Physicians? However, the difficulty of certain community doctors and paediatricians working in small units in obtaining CME credits is sufficient justification for a separate BPA scheme which will enable the association to identify these doctors and help them in their continuing education.

The definition of the types of CME educational activity has also been queried. External CME emphasises less where it takes place than the importance of interacting with paediatricians and other colleagues outside any particular unit and in time which is protected, often through study leave. Thus, it is possible for some doctors to have external CME on site if there is an opportunity to learn from others and provided that their work commitments are completely covered.

Implicit in the philosophy of CME is that most paediatricians are already contributing to 
maintaining their clinical effectiveness and keeping up to date on knowledge by reading journals, participating in meetings, etc. However, the BPA pilot scheme did not recognise teaching and academic activities whether undergraduate, postgraduate, examination activities, writing books or other articles - for accreditable CME and justification has been given for this above. Our study has shown that most of those who would wish to have these teaching activities approved for CME are working in some of the bigger institutions and have little difficulty in obtaining credits. We are more concerned that doctors who are less fortunate should be given protected time to attend both internal and external activities. However, we also recognise that the role of teaching and academic activities, management, information technology and other activities, are among the many aspects of $\mathrm{CME}$ which will need to be kept under regular review.

The BPA national scheme for CME will start on 1 January 1996. Details of the scheme are given in a document ${ }^{3}$ which is being distributed to all career grade paediatricians; most of these details are the same as those in the pilot scheme. A significant change concerns the credits (hours) given for activities taking place over days. One whole study day will now normally be allocated five hours of educational time, with a maximum of seven hours for those days where evening sessions are included; half a day will be allocated three hours. This differs slightly from the allocations of other medical colleges and their faculties. Also at variance are some of the categories of CME described in the appendix.

Participation in CME is a professional obligation for all career grade paediatricians. Individual paediatricians must accept their responsibilities to ensure a balanced CME programme of learning experiences appropriate to particular needs, to keep an accurate and up to date record and to make returns every three months and annually as required. It is also important to work towards requirements for CME being built into job descriptions and contractual arrangements. We have drawn attention to the fact that overall the target of 50 hours per year will be achieved with relative ease. This means in practice only one hour every other week of internal CME and five days external CME (that is, half the annual study leave entitlement). We are concerned, however, that, on the basis of the pilot scheme, only one in two paediatricians would achieve 100 hours per year (the projected target in a couple of years).

A list of those who have fulfilled CME requirements will be maintained by the BPA. Satisfactory completion of a five year cycle will earn a certificate of completed CME. The consequence of not accumulating sufficient $\mathrm{CME}$ credits has yet to be decided. This could mean loss of training status, exclusion from BPA/college committees, etc. Every opportunity will be offered to explore individual cases before any sanction, if there is to be any sanction, will be imposed.
The pilot scheme has also exposed uncertainties about the approval of CME activities. The national scheme proposes that regional advisers and their deputies are key players in the approval process, supported by BPA tutors. Their responsibilities will be principally to judge whether meetings held in their regions, other than those automatically given approval, are appropriate for external CME and to agree, using whatever method is considered appropriate, the suitability of internal CME. A detailed checklist is provided in the BPA scheme to help those who will be organising CME activities. It is important, however, to emphasise again that regional advisers will be facilitating $\mathrm{CME}$, with the CME office of the BPA always available to advise should any problems occur. Individual career grade paediatricians will have to take responsibility themselves for becoming fully conversant with the recommendations and for fulfilling the requirements.

We have no evidence that the CME system that we (or any other college or faculty) are recommending will fulfil the educational objectives of CME. How should the effectiveness of CME be audited? What we are recommending is a structure which is built on an already existing edifice of learning activities and which the pilot scheme tells us is workable. A more formal structure is now being demanded and it is important that the BPA is seen to be looking after the interests of its membership. As the scheme is implemented questions will inevitably emerge, but a start must be made. The CME subcommittee will review progress and prepare annual reports, at least in the early years. It is possible that criteria for the various activities will change. Is it reasonable, for example, to expect sessional and part time doctors to have to reach the same target as full time doctors, as all directors of $\mathrm{CME}$ of the royal colleges and their faculties have had to agree? CME is a fluid activity; it is not cast in tablets of stone. However, this will be something for the future.

The time for talking is now over - the time for action is near!

'I see you stand like greyhounds in the slips, Straining upon the start. The game's afoot; Following your spirit: and upon this charge Cry .........'

1 National Health Service Executive. Consultation paper issued for the chief medical officer's conference on continuing education for doctors and dentists. London: NHS Executive, June 1994

2 British Paediatric Association. Pilot scheme for continuing medical education: CME for trained paediatricians - recommendations by the academic board for a pilot scheme to implement CME. London: BPA, September 1994.

3 British Paediatric Association. Continuing medical education for career grade paediatricians - recommendations by the academic board of the British Paediatric Association for the national scheme. London: BPA, December 1995.

\section{Appendix}

CONTINUING EDUCATION ACTIVITIES

QUALIFYING FOR CME IN THE PILOT SCHEME

External CME (requiring professional study leave, ECME)

Internal $\mathrm{CME}$ (not requiring professional study leave, ICME) 
Category $A$ - international and national meetings (ECME)

1. Meetings organised under the auspices of the BPA:

(a) Annual Meeting

(b) Specialty group meetings

2. Meetings organised by the royal colleges and the Royal Society of Medicine

3. International clinical or scientific meetings

Category $B$ - regional meetings (ECME/ICME)

Category $C$ - local meetings (ICME)

For example weekly unit clinical meetings/ hospital grand rounds/journal club/audit

Category D - research meetings (ECME)

Research society meetings - for example
Paediatric Research Society/Neonatal Society/ specialty research groups

Category $E$ - self directed activities (ICME)

1. Self learning/prepared teaching packages/ distance courses

2. Specially prepared postgraduate lectures

Category $F$ - courses/apprenticeship activities

(ECME/ICME)

1. Specific courses

2. Apprenticeship activities for individuals wishing to learn new practical techniques or to update clinical management skills (for example, endoscopy/management of epilepsy)

3. Learning from colleagues in inpatient/outpatient/community situations 